\title{
Aluminium hydroxide versus sucralfate as a phosphate binder in uraemia
}

\author{
A C T LEUNG, I S HENDERSON, D J HALLS, J W DOBBIE
}

\begin{abstract}
In an attempt to discover a phosphate binding agent for use in uraemia that would not lead to appreciable systemic absorption of aluminium the effect of sucralfate was evaluated after three weeks and compared with that of the existing standard agent aluminium hydroxide. Sucralfate caused a decrease in serum phosphate concentration comparable with that obtained with aluminium hydroxide, but similar absorption of aluminium resulted.
\end{abstract}

Sucralfate may be the phosphate binder of choice in patients with uraemia and peptic ulceration; care should be taken in using large doses of the drug in patients with normal renal function.

\section{Introduction}

Recent reports have indicated that aluminium,which is normally cleared by the kidney, may accumulate in patients receiving regular haemodialysis, resulting in extreme cases in encephalopathy or osteomalacia. ${ }^{1-4}$ Although the major source of aluminium in most series has been non-deionised water used in preparing the dialysate, ${ }^{56}$ a considerable contribution may come from the use of large quantities of oral aluminium hydroxide as a phosphate binder in uraemia. ${ }^{7}$ Even in continuous ambulatory peritoneal dialysis, when the dialysate should contain minimal quantities of aluminium, appreciable increases in

University Department of Medicine, Glasgow Royal Infirmary, Glasgow G4 0SF

A C T LEUNG, MB, MRCP, registrar

I S HENDERSON, MB, MRCP, senior registrar

J W DOBBIE, MD, FRCP, senior lecturer

Biochemistry Department, Glasgow Royal Infirmary

D J HALLS, PHD, senior biochemist

Correspondence to: Dr A C T Leung, Renal Unit, Glasgow Royal Infirmary, Glasgow G4 OSF. serum aluminium concentrations have been documented after the start of oral treatment with aluminium hydroxide. ${ }^{8}$

The search for an effective phosphate binding agent for patients with impaired renal function that would not result in appreciable accumulation of aluminium led us to examine the basic aluminium salt of sucrose octasulphate (sucralfate). This drug has recently been described for use in the treatment of peptic ulceration, and claims have been made that it is at least as effective as cimetidine. ${ }^{910} \mathrm{It}$ is not an antacid, and its action has been attributed to the formation of an intragastric paste that binds to tissue protein at the base of the ulcer crater. The paste also adsorbs pepsinogen and bile acids, and long term studies have indicated that little or no systemic aluminium absorption occurs in patients with ulcers and normal renal function. ${ }^{11}$

We conducted a comparative study of aluminium hydroxide and sucralfate in 12 patients receiving dialysis, assessing both phosphate binding ability and absorption of aluminium.

\section{Patients and methods}

We studied 12 patients with end stage chronic renal failure who had been maintained on regular dialysis for more than four month (mean 10 months). Six patients were receiving continuous ambulatory peritoneal dialysis (four exchanges a day) and six hospital haemodialysis (12 hours a week). All patients were receiving regular ora aluminium hydroxide (Alu-cap, Riker), the mean dosage being six capsules a day. Table I shows clinical details of the patients.

During the course of the study the patients took their normal diets and the duration and frequency of dialysis sessions were kept constant. All antacids other than aluminium hydroxide were stopped. Three study periods were adopted, each lasting three weeks. In the first patients took their regular dosage of aluminium hydroxide; in the second aluminium hydroxide was stopped; and in the third sucralfate (Antepsin, Ayerst) was substituted for aluminium hydroxide on the basis of $1 \mathrm{~g}$ sucralfate for $475 \mathrm{mg}$ aluminium hydroxide (both containing about $160 \mathrm{mg}$ of elemental aluminium).

At the end of each study period venous blood samples were taken (immediately before dialysis in patients receiving haemodialysis and after a six hour cycle in patients receiving continuous ambulatory peritoneal dialysis) and analysed for calcium, phosphate, and aluminium. Results were compared using Student's $t$ test. Assays for calcium and phosphate were by the standard automated methods. 
Serum samples were assayed for aluminium by graphite furnace atomic absorption spectrometry using the method developed by Gardiner et al.12 Samples were diluted three times with deionised water and analysed against standards of aluminium nitrate in water. The apparatus consisted of a Perkin-Elmer 272 spectrometer with an HGA 400 furnace, AS 1 autosampler, and model 56 recorder.

TABLE I-Clinical details and method of treatment of patients in study

\begin{tabular}{cccllc}
\hline $\begin{array}{c}\text { Case } \\
\text { No }\end{array}$ & $\begin{array}{c}\text { Age } \\
\text { (years) }\end{array}$ & Sex & Treatment & \multicolumn{1}{c}{ Renal diagnosis } & $\begin{array}{c}\text { Daily dose of } \\
\text { aluminium } \\
\text { hydroxide } \\
\text { (No of } \\
\text { Alu-cap } \\
\text { capsules) }\end{array}$ \\
\hline 1 & 46 & M & CAPD & Hypertensive nephrosclerosis & 9 \\
2 & 52 & M & CAPD & Chronic pyelonephritis & 3 \\
3 & 58 & M & CAPD & Chronic glomerulonephritis & 9 \\
4 & 46 & F & CAPD & Chronic pyelonephritis & 9 \\
5 & 53 & M & CAPD & Polycystic kidneys & 6 \\
6 & 60 & M & CAPD & Hypertensive nephrosclerosis & 6 \\
7 & 58 & F & Haemodialysis & Interstitial nephritis & 6 \\
8 & 48 & M & Haemodialysis & Chronic glomerulonephritis & 3 \\
9 & 37 & F & Haemodialysis & Systemic lupus erythematosus & 3 \\
10 & 46 & F & Haemodialysis & Chronic pyelonephritis & 6 \\
11 & 15 & M & Haemodialysis & Chronic glomerulonephritis & 6 \\
12 & 51 & M & Haemodialysis & Chronic pyelonephritis & 9 \\
\hline
\end{tabular}

$\mathrm{CAPD}=$ Continuous ambulatory peritoneal dialysis

TABLE II-Mean $(t S D)$ serum calcium, phosphate, and aluminium concentrations at end of each study period in six patients receiving continuous ambulatory peritoneal dialysis (CAPD) and six receiving haemodialysis*

\begin{tabular}{|c|c|c|c|}
\hline & $\begin{array}{c}\text { Aluminium } \\
\text { hydroxide taken }\end{array}$ & $\begin{array}{l}\text { No aluminium } \\
\text { hydroxide }\end{array}$ & Sucralfate taken \\
\hline \multicolumn{4}{|c|}{ Phosphate (mmol/l) } \\
\hline $\begin{array}{l}\text { CAPD } \\
\text { Haemodialysis } \\
\text { All patients }\end{array}$ & $\begin{array}{l}1.98 \pm 0.44 \\
1.90 \pm 0.74 \\
1.94 \pm 0.58\end{array}$ & 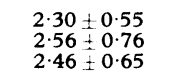 & $\begin{array}{l}1.71 \pm 0.35 \\
1.75 \pm 0.45 \\
1.73 \pm 0.45\end{array}$ \\
\hline \multicolumn{4}{|c|}{ Calcium $(\mathrm{mmol} / \mathrm{l})$} \\
\hline $\begin{array}{l}\text { CAPD } \\
\text { Haemodialysis } \\
\text { All patients }\end{array}$ & $\begin{array}{l:l}2 \cdot 29 & 0 \cdot 11 \\
2 \cdot 32 & 0 \cdot 25 \\
2 \cdot 30 & 0 \cdot 19\end{array}$ & $\begin{array}{l}2 \cdot 25 \pm 0 \cdot 21 \\
2 \cdot 25 \pm 0 \cdot 23 \\
2 \cdot 23+0 \cdot 23\end{array}$ & $\begin{array}{l}2 \cdot 30+0 \cdot 14 \\
2 \cdot 30+0 \cdot 23 \\
2 \cdot 30 \pm 0 \cdot 17\end{array}$ \\
\hline \multicolumn{4}{|c|}{ Aluminium $(\mu \mathrm{mol} / \mathrm{l})$} \\
\hline $\begin{array}{l}\text { CAPD } \\
\text { Haemodialysis } \\
\text { All patients }\end{array}$ & $\begin{array}{l}1 \cdot 80 \pm 0 \cdot 60 \\
2 \cdot 10 \pm 1 \cdot 20 \\
1 \cdot 90 \pm 1 \cdot 20\end{array}$ & $\begin{array}{r}0.80 \pm 0.50 \\
1.6 \pm 0.60 \\
1 \cdot 20 \pm 0.60\end{array}$ & $\begin{array}{l}2 \cdot 00+0.90 \\
2 \cdot 10+1.00 \\
2.00+1.00\end{array}$ \\
\hline
\end{tabular}

*Aluminium concentrations in dialysate: haemodialysis $0.7 \mu \mathrm{mol} / 1(1.9 \mu \mathrm{g} / 100 \mathrm{ml})$; continuous ambulatory peritoneal dialysis $<0 \cdot 1 \mu \mathrm{mol} / 1(0 \cdot 3 \mu \mathrm{g} / 100 \mathrm{ml})$. Conversion: SI to traditional units-Phosphate: $1 \mathrm{mmol} / 1 \approx 3.1 \mathrm{mg} / 100 \mathrm{ml}$
Calcium: $1 \mathrm{mmol} / 1 \approx 4 \mathrm{mg} / 100 \mathrm{ml}$. Aluminium: $1 \mu \mathrm{mol} / 1 \approx 2 \cdot 7 \mu \mathrm{g} / 100 \mathrm{ml}$.

\section{Results}

Table II shows the results. Serum calcium concentrations were not affected when patients stopped taking aluminium hydroxide or when they took sucralfate instead. Serum phosphate concentrations were adequately controlled with aluminium hydroxide but showed a significant rise $(\mathrm{p} \leqslant 0.0125)$ in all patients after aluminium hydroxide was stopped followed by an equally significant fall when sucralfate was taken. Baseline aluminium concentrations were comparable in both groups of patients. Three weeks after aluminium hydroxide was stopped they showed a significant fall $(p \leqslant 0.0125)$ in both groups, which was slightly greater in the patients receiving continuous ambulatory peritoneal dialysis. After three weeks of treatment with sucralfate concentrations had risen significantly $(p \leqslant 0.01)$, reaching baseline values.

Patients tolerated both forms of treatment well, though some found sucralfate difficult to swallow. Two patients with proved chronic duodenal ulceration obtained almost complete remission of their dyspeptic symptoms, and one was able to stop taking ranitidine.

\section{Discussion}

This study suggests that sucralfate is a phosphate binding agent comparable in potency with aluminium hydroxide and indicates that it may have a useful place in the management of hyperphosphataemia in uraemia.
Aluminium may be absorbed from the gastrointestinal tract $\underline{\underline{T}}$ in quite large quantities after administration of aluminium 3 hydroxide..$^{13}$ As most 'free' aluminium exists when aluminium $\stackrel{\mathbb{Q}}{\varrho}$ hydroxide is exposed to acid $\mathrm{pH}$ conditions, absorption probably $\mathrm{C}$ occurs in the stomach, although Berlyne et al suggested that the $\widehat{\Omega}$ intestine was the most likely site. ${ }^{7}$ Elimination from the body depends on intact renal function, and appreciable concentrations accumulate in chronic renal failure. ${ }^{12}$ The presence of high $\mathbb{D}$ aluminium concentrations in dialysate used in haemodialysis ${ }^{6}$ or continuous ambulatory peritoneal dialysis ${ }^{14}$ has been associated with serious toxic consequences. Our finding of a fall in serum $\vec{\Rightarrow}$

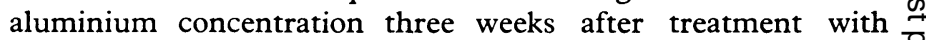
aluminium hydroxide was stopped accords with the finding of Fleming et $a l^{8}$ and provides yet further confirmation of the $\overline{\bar{D}}$ appreciable contribution made by oral administration of aluminium to systemic accumulation in uraemia. We should point out, however, that basal aluminium concentrations at $\approx$ the start of our study were below the ranges previously docu- $\overrightarrow{0}$ mented as toxic. ${ }^{6}$

Several observers have commented that serum aluminium $\vec{\omega}$ concentrations are lower in continuous ambulatory peritoneal $\frac{\partial}{\partial}$ dialysis than haemodialysis. ${ }^{815}$ Suggested reasons are that continuous ambulatory peritoneal dialysis removes phosphate i more completely, so that less aluminium hydroxide is required, \& or that dialysate concentrations of aluminium are very low, $\dot{\omega}$ promoting better removal. ${ }^{15}$ In our survey aluminium hydroxide $\mathrm{W}$ requirements and basal aluminium concentrations were similar $\vec{\omega}$ in both groups but when aluminium hydroxide was stopped the serum aluminium concentration appeared to fall further in patients receiving continuous ambulatory peritoneal dialysis in whom the dialysate aluminium concentration was con- $\mathscr{O}$ siderably lower.

Nagashima and Yoshida suggested that because of the formation of a paste in the stomach and the physicochemical $\overrightarrow{\vec{\theta}}$ properties of sucralfate in acid media few or no aluminium $\infty$ ions should be available for absorption. ${ }^{16}$ In long term studies in patients with peptic ulcer and normal renal function Kinoshita et al could not show any rise in serum aluminium concentrations, ${ }^{11}$ although urine aluminium concentrations were not measured so that efficient renal clearance may have masked appreciable absorption. Our results indicate that absorption $\stackrel{\Phi}{\varrho}$ of aluminium with sucralfate was much the same as that with $\overrightarrow{\vec{\theta}}$ aluminium hydroxide. We were unable to determine accurately whether the presence of peptic ulceration might diminish $\bar{P}$ absorption of aluminium, although serum aluminium concentrations were not apparently lower in our two subjects with peptic ulcer disease.

The ulcer healing properties of sucralfate indicate that it may be the phosphate binder of choice in uraemic patients with peptic ulcers. Certainly, two of our subjects with proved duodenal ulcers experienced improvement in dyspeptic symptoms. Because of its effective phosphate binding action sucralfate

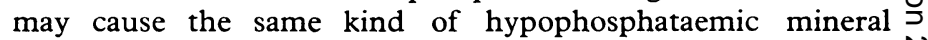
metabolic upset encountered with antacid treatment, and $N$ caution should be exercised with the use of large doses in $D$ patients with normal renal function. ${ }^{17}$

\section{References}

${ }^{1}$ Flendrig JA, Kruis H, Das HA. Aluminium intoxication: the cause of dialysis dementia? Proc Eur Dial Transplant Assoc 1976;13:355-61.

" McDermott JR, Smith AI, Ward MK, Parkinson IS, Kerr DNS. Brainaluminium concentration in dialysis encephalopathy. Lancet 1978; ; 901-3.

${ }^{3}$ Alfrey AC, LeGendre GR, Kaehny WD. The dialysis encephalopathy syndrome. Possible aluminium intoxication. New Engl $\mathcal{f}$ Med 1976; 294:184-8.

1 Ward MK, Feest TG, Ellis HA, et al. Osteomalacic dialysis osteodystrophy: evidence for a water-borne aetiological agent, probably aluminium. Lancet $1978 ; \mathrm{i}: 841-5$.

${ }^{5}$ Platts MM, Goode GC, Hislop JS. Composition of the domestic water supply and the incidence of fractures and encephalopathy in patients on home dialysis. Br Med $\mathcal{F} 1977$;ii :657-60. 
${ }^{6}$ Elliott HL, Dryburgh F, Fell GS, Sabet S, MacDougall AI. Aluminium toxicity during regular haemodialysis. Br Med f 1978;ii:1101-3.

${ }^{7}$ Berlyne GM, Ben-Ari J, Pest D, et al. Hyperaluminaemia for aluminium resins in renal failure. Lancet 1970;ii:494-6.

"Fleming LW, Stewart WK, Fell GS, Halls DJ. The effect of oral aluminium therapy on plasma aluminium levels in patients with chronic renal failure in an area with low water aluminium. Clin Nephrol 1982; $17: 222-7$

${ }^{9}$ Fisher RS. Sucralfate: a review of drug tolerance and safety. $\mathcal{F}$ Clin Gastroenterol $1981 ; 3$,suppl 2:181-4.

${ }^{10}$ Hollander D. Efficacy of sucralfate for duodenal ulcers: a multicenter, double-blind trial. $₹$ Clin Gastroenterol $1981 ; 3$,suppl 2:153-7.

${ }^{11}$ Kinoshita H, Kumaki K, Nakano H, et al. Plasma aluminium levels of patients on long term sucralfate therapy. Res Commun Chem Pathol Pharmacol 1982;35:515-7.

12 Gardiner PE, Ottaway JM, Fell GS, Halls DJ. Determination of alu- minium in blood plasma or serum by electrothermal atomic absorption spectrometry. Analytica Chimica Acta 1981;128:57-66.

${ }^{13}$ Kaehny WD, Hegg AP, Alfrey AC. Gastrointestinal absorption of aluminium from aluminium-containing antacids. New Engl $\mathcal{f} \mathrm{Med}$ $1977 ; 296: 1389-90$

14 Cumming AD, Simpson G, Bell D, Cowie J, Winney RJ. Acute aluminium intoxication in patients on continuous ambulatory peritoneal dialysis. Lancet $1982 ; \mathrm{i}: 103-4$.

15 Wolf A, Graf H, Pinggera WF, Stummvoli HK, Meisinger V. Serum aluminium and continuous ambulatory peritoneal dialysis. Ann Intern Med 1980;92:130-1.

${ }^{16}$ Nagashima R, Yoshida N. Sucralfate, a basic aluminium salt of sucrose sulphate. Arzneim Forsch 1980;30:73-80.

17 Spencer $\mathrm{H}$, Lender $M$. Adverse effects of aluminium-containing antacids on mineral metabolism. Gastroenterology 1979;76:603-6.

(Accepted 10 March 1983)

\title{
Sweat tests to diagnose cystic fibrosis in adults
}

\author{
MARGARET E HODSON, IRENE BELDON, RUTH POWER, FRANCIS R DUNCAN, \\ MAY BAMBER, J C BATTEN
}

\begin{abstract}
Twenty five patients with cystic fibrosis and 25 controls were studied to define a sweat sodium concentration in adults that could be taken as diagnostic of cystic fibrosis. Some of the controls had a sweat sodium concentration of over $50 \mathrm{mmol}(\mathrm{mEq}) / 1$, and thus cystic fibrosis should be diagnosed in an adult only when two measurements of sweat sodium concentration are above $70 \mathrm{mmol} / \mathrm{l}$. In cases in which the sweat sodium concentration was borderline a suppression test using fludrocortisone improved the accuracy of diagnosis; this test entails recording the lowest concentration reached after administration of the drug. A scatter diagram of the baseline sweat sodium concentrations plotted against the lowest concentration attained after suppression with fludrocortisone may aid the diagnosis further.
\end{abstract}

\section{Introduction}

The sweat test is accepted as an essential diagnostic test for cystic fibrosis in childhood. Normal adults have a higher sweat sodium concentration than normal children, and the test may therefore be less reliable in adults.' Di Sant'Agnese and Davis stated, however, that the criteria for diagnosing cystic fibrosis were similar in adults and children-namely, the presence of raised sweat chloride and sodium $(>50-60 \mathrm{mmol}(\mathrm{mEq}) / \mathrm{l})$ concentrations and either chronic pulmonary disease or pancreatic sufficiency." Shwachman et al commented that "one can interpret the sweat test in adults with the same degree of reliability as in children." 3 Modifications of the sweat test using aldosterone or fludrocortisone have been advocated. ${ }^{4} 5$ Most of these reports, however, concern children rather than

Brompton Hospital and Cardiothoracic Institute, London SW3 6HP MARGARET E HODSON, MD, MRCP, clinical senior lecturer in thoracic medicine and honorary consultant physician

IRENE BELDON, BSC, FIMLS, medical laboratory scientific officer

RUTH POWER, SRN, nursing sister, cystic fibrosis unit

FRANCIS R DUNCAN, SRN, clinical nurse specialist, cystic fibrosis unit MAY BAMBER, MB, MRCP, senior house officer

J C BATTEN, MD, FRCP, consultant physician

Correspondence to: $\mathrm{Dr} \mathrm{M}$ E Hodson, Cardiothoracic Institute, Fulham Road, London SW3 6HP. adults. The aim of the present study was to define a sweat sodium concentration in adults that could be taken as diagnostic of cystic fibrosis and to study the effect of fludrocortisone on sweat sodium concentrations in normal adults and adults with cystic fibrosis.

\section{Subjects and methods}

Sweat tests were performed on 25 patients with cystic fibrosis (10 male, 15 female; age range 15-36). The controls consisted of 25 fit adults (13 men, 12 women; age range 19-40). Sweat tests were performed using pilocarpine iontophoresis ${ }^{6}$ and the sodium concentration measured by flame photometry. All sweat tests were performed by a laboratory scientific officer or a nursing sister experienced in the technique. In each case over $100 \mathrm{mg}$ sweat was collected. Great care was taken that the filter paper was not contaminated by the investigator's sweat, and while sweat was being collected the filter paper was completely occluded by an airtight dressing to prevent loss of water by evaporation. All tests were performed in duplicate. Only duplicate readings that did not vary by more than $8 \mathrm{mmol} / \mathrm{l}$ were accepted.

Sweat tests were performed on day 1 . On days 2 and 3 all 50 subjects received $5 \mathrm{mg}$ fludrocortisone, and on days 4 and 5 the sweat tests were repeated. Fig 1 shows the results of the sweat tests over the five days in two controls and two patients with cystic fibrosis. The baseline value on day 1 and the lowest concentration reached on either day 4 or day 5 were recorded; the percentage suppression was calculated from these values. Statistical analysis was by discriminant analysis.?

\section{Results}

The mean $(2 \mathrm{SD})$ baseline sweat socium concentration was $43.20(+35 \cdot 3) \mathrm{mmol} / \mathrm{l}$ in the controls and $i(1) \cdot 1) 4(+31 \cdot 8) \mathrm{mmol} / \mathrm{l}$ in the patients with cystic fibrosis $(\mathrm{p}<0.001)$. Tinree of the 25 controls had concentrations of over $60 \mathrm{mmol} / \mathrm{l}$ (fig 2 , . The mean percentage suppression of sweat sodium concentration after administration of fludrocortisone was $26.32(.29 .9) \%$ in the controls and $8.08(+16.9) \%$ in the patients $(0.01>p>0.001)$ (fig 3). The mean of the iowest sweat sodium concentrations attained after suppression with fludrocortisone was $31.56(-27.5) \mathrm{mmol} / 1$ in the controls and $95 \cdot 6(-31 \cdot 3) \mathrm{mmol} / \mathrm{l}$ in the patients $(\mathrm{p}<0.001)$ (fig 4$)$. (No dup icate readings varied by more than $8 \mathrm{mmol} / \mathrm{l}$.)

Statistical analysis of the overlap between the distributions indicated that if a baseline sweat sodium concentration of above $60 \mathrm{mmol} / \mathrm{l}$ was regarded as being diagnostic of cystic fibrosis $17 \cdot 11 \%$ of controls and $0.34 \%$ of patients would be misclassified; and if $70 \mathrm{mmol} / \mathrm{l}$ was used $6.43 \%$ of controls and $1.88 \%$ of patients would 